\title{
QUEEN'S
UNIVERSITY
BELFAST
}

\section{Being counted? Examining the prevalence of looked-after disabled children and young people across the UK.}

Hill, L., Baker, C., Kelly, B., \& Dowling, S. (2015). Being counted? Examining the prevalence of looked-after disabled children and young people across the UK. Child and Family Social Work, 22(1), 287.

https://doi.org/10.1111/cfs.12239

Published in:

Child and Family Social Work

Document Version:

Early version, also known as pre-print

Queen's University Belfast - Research Portal:

Link to publication record in Queen's University Belfast Research Portal

\section{Publisher rights}

(C) 2015 The authors

This is the pre-peer reviewed version of the following article: Hill, L., Baker, C., Kelly, B. and Dowling, S. (2015), Being counted? Examining the prevalence of looked-after disabled children and young people across the UK. Child \& Family Social Work., which has been published in final form at http://onlinelibrary.wiley.com/doi/10.1111/cfs.12239/abstract;jsessionid=9D693BE09972B94952293D5F37492C72.f03t01. This article may be used for non-commercial purposes in accordance with Wiley Terms and Conditions for Self-Archiving.

\section{General rights}

Copyright for the publications made accessible via the Queen's University Belfast Research Portal is retained by the author(s) and / or other copyright owners and it is a condition of accessing these publications that users recognise and abide by the legal requirements associated with these rights.

\section{Take down policy}

The Research Portal is Queen's institutional repository that provides access to Queen's research output. Every effort has been made to ensure that content in the Research Portal does not infringe any person's rights, or applicable UK laws. If you discover content in the Research Portal that you believe breaches copyright or violates any law, please contact openaccess@qub.ac.uk. 
Being Counted? Examining the prevalence of looked after disabled children and young people across the United Kingdom

\section{Abstract}

Since the 1970s, there has been growing academic interest in children and young people living in state care and, more recently, in the lives of disabled children. However, there has been little attention on the lives of disabled children who are looked after by the state. This paper compares and critiques what is known about the numbers of disabled children who are looked after in England, Northern Ireland, Scotland and Wales. We discuss the conceptual and methodological limitations of systematically collecting data on disabled children in state care across the United Kingdom. We argue that to ensure the rights of disabled children in state care are identified, acknowledged and upheld, 'being counted' is a fundamental first step.

Key Words (6): Disabled children, Looked after children, child welfare, children's services, prevalence studies. 


\section{Introduction}

In 1991, the United Kingdom government ratified the United Nations Convention on the Rights of the Child (UNCRC) (1989). Under the UNCRC (1989), special consideration should be given to children who are cared for by the state (Article 20) and to disabled children (Article 23). All children have the right to live free from abuse and neglect (Article 19) and the right to express their views in matters that affect their lives (Article 12). Subsequent ratification of the UN Convention on the Rights of Persons with Disabilities (UNCRPD) (2007) set out the rights of all disabled persons, including children, to live free from discrimination and requires appropriate measures to ensure that their full human rights are upheld. This international recognition enshrining the rights of disabled children who are cared for by the state may reflect ongoing concern that this group of children are particularly vulnerable to rights violations and abuse (Morris, 1995; Read \& Harrison, 2002; Stalker \& McArthur, 2012). This article critically explores what is known about the number of disabled children who are looked after across the United Kingdom as a fundamental first step in ensuring the rights of this specific group of children are upheld.

In Great Britain, the Equality Act 2010 defines disability as a physical or mental impairment that has a 'substantial' and 'long-term' negative effect on your ability to do normal daily activities (Equality Act 2010, Section 6). In Northern Ireland, a similar definition is provided in the Disability Discrimination Act (1995, Part 1) which defines disability as: "a physical or mental impairment that has substantial or long-term effect on a person's ability to carry out normal day-to-day activities". There are an estimated 800,000 disabled children and young people in the United Kingdom using the definition of disabled to include a long-standing illness, disability or impairment which causes substantial difficulty with day-to-day activities (DWP 2013). In a review of UK quantitative data sources on the prevalence of childhood disability in the general population, Read and colleagues (2009, p. 140) argue 'there is no single way of defining disability, and therefore, of course no 'golden estimate' of prevalence of 
childhood disability'. As we will discuss, a variety of definitions of disability are applied to estimate the prevalence of disabled children in state care across jurisdictions.

Introduced under the 1989 Children Act for England and Wales, the term 'looked after' refers to children for whom the local authority has a set of specific legal responsibilities which may include accommodating a child and legally obtaining parental responsibility. This is similarly defined under the 1995 Children (Scotland) Act and 1995 Children Order (Northern Ireland). Children may also be looked after under a voluntary agreement with birth parents where parents retain legal parental responsibility. However, the majority of looked after children will no longer live with their birth parents due to state intervention; children may reside in foster care, residential care, secure care settings and kinship care. As of 31 March 2014, 68,840 children in England, 2,807 children in Northern Ireland and 5,755 children in Wales were looked after by the state (Department for Education 2014; DHSSPSNI 2013; Welsh Government 2014a). In Scotland, 15,580 children were looked after as of July 2014 (Scottish Government 2015). In all four countries, national policy is to work in partnership with families, where safe and appropriate to do so, to minimise the number of children becoming looked after by the state. Furthermore, a child may be legally looked after for a short period of time with the aim of family reunification following a period of intensive support. England has the largest number of looked after children, whilst Scotland has the highest rate of looked after children, which is partly explained by just over a quarter of children (26.6\%) being looked after at home on supervision orders with their birth parents (Scottish Government 2015).

In recognition of the significant gap of information on this topic, a knowledge exchange programme entitled: Getting it Right for Looked after Disabled Children and Young People was held between October 2012 and April 2013 funded by the Scottish Universities' Insight Institute. The aim of the programme was to explore the experiences of looked after disabled children and young people and consider how these are reflected in research, policy and practice arenas. A series of thematic 
workshops were developed: Being Counted (October 2012), Being Heard (December 2012), Being Included (February 2013) and Being Valued (April 2013) to bring together academics, policy makers, service practitioners, third sector organisations and service user organisations from across the United Kingdom. Stemming from the Being Counted seminar, this paper compares current prevalence rates of looked after disabled children across England, Northern Ireland, Scotland and Wales and discusses the methodological and conceptual limitations in data collection.

\section{Background}

The interaction between disabled children, birth parents and the state can be complex and has changed over time. Across the UK and internationally, there is a long history of residential care for children who could not remain living with their birth families and this has disproportionately impacted on disabled children (Milligan \& Stevens 2006; Smith 2009). Historically, families would often be provided with limited support from the state to care for their disabled child at home and, if this was not possible, the only option usually offered to families was placement of their child in residential care (Argent 1996). From the 1970s, there was an increasing recognition that foster care and adoption could play a role in caring for some disabled children leading to a move away from residential establishments. A small number of specialist agencies were established for placing older and severely disabled children in foster care and adoptive families and their work demonstrated that, with the right support, such arrangements could be successful (Argent 1998). Despite these intentions, progress has been slow. In a seminal study of disabled children living away from their families, Morris (1995, p. 89) found that disabled children had 'patterns of care which would never be tolerated for non-disabled children'; for example, disabled children were remaining in inappropriate residential care placements and foster care and adoption were not routinely considered. More recently, research evidence suggests there are challenges to achieving family models of care and disabled children can be "hard to place' (Baker 2011; Cousins 2006; Grant \& Thomas 2013). 
Disabled children can also be looked after by the state due to their episodic use of specific care placements for short breaks (Kelly et al. 2014; Dowling et al. 2013). Short breaks are defined as a planned period of time where a disabled child is cared for away from the family home. Various different terms are used to refer to this group of children, including 'short breaks', 'family link placements', 'shared care' and 'respite care'. This may include a short period of placement in foster care, residential care, residential schools or hospital settings. Across the UK if a child is away from the family home for over 24 hours this would become a period of being looked after; however, there are different rules across the different jurisdictions as to whether these periods of care are counted in the national looked after statistics for all children. In McGill et al.'s (2006) UK study with parents whose children are in a 52 week a year residential setting, there is significant variation due to funding arrangements between education and social services as to whether or not a child is legally considered to be a looked after child. The study found that children who are funded through education authorities are not always granted looked after status, and highlighted 'this is, clearly, of particular concern when the children involved are in 52-week placements and may have limited contact with their parents' (McGill et al. 2006, p. 599). Local policy and practice often determines whether a child who uses short break services is considered to have 'looked after' status.

Across all UK territories the main reason why children enter the care system is due to concerns about abuse and neglect. We know from international research that disabled children are more likely to experience abuse and neglect than their non-disabled peers (Jones et al. 2012; Stalker \& McArthur 2012; Sullivan \& Knutson 2000). Thus hypothetically, disabled children may be more likely to enter care than their non-disabled peers. A retrospective whole-population cohort study of infants born between January 1983 and December 2001 in West Sussex (England), explored the relationship between disability and registration for child abuse and neglect (Spencer et al. 2005). The study found that disabled children, especially those with conduct disorders and learning difficulties, were at increased risk of registration for child abuse and neglect compared to the general child population. 
The authors highlighted that some types of impairment(s) 'shared common etiologic pathways with abuse, which makes it difficult to ascertain if the abuse is precipitated by the child's condition or arises in parallel with the disability' (Spencer et al. 2005, p. 612). There is a possibility that a child's disability may not be fully known or understood until the child is removed from an abusive environment and a period of child development assessment is undertaken. Furthermore, direct disclosure of abuse by disabled children can be more difficult; children require appropriate communication tools and for professionals to be willing to listen and recognise signs of abuse (Hershkowitz et al. 2007; Stalker \& McArthur, 2012). Therefore, for this category, it is particularly difficult to establish an accurate prevalence rate.

\section{Estimating the numbers of looked after disabled children across the UK}

As there are distinct approaches to collecting data on the population of looked after disabled children across the UK, this section of the paper will examine the sources of data for each jurisdiction to identify the extent of the population and highlight gaps in statistical data available.

\section{England}

In England official statistics are annually collected on children who are looked after and who have recently left care (for the year ending $31^{\text {st }}$ March) from 152 local authorities. These statistics do not record whether or not a child has a disability. As a result answering the question of how many looked after children are disabled is problematic and often reliant on out-of-date and incomplete evidence. Local authorities may record indirectly if a looked after child is disabled when this is considered to be the primary reason for children's services intervention (known as the 'category of need code'). However, children can be looked after for a number of reasons. Local authorities are required to condense such details and record a child's primary need code from a list of eight possibilities: abuse and neglect; child's disability; parental illness/disability; family in acute stress; family dysfunction; 
socially unacceptable behaviour; low income and absent parenting. One of these need codes relates to a 'child's disability' which is defined as 'children and their families whose main need for services arises out of the children's disabilities, illness or intrinsic condition'. The latest statistics in England show that only $3 \%(2,320)$ of looked after children (DfE 2014) had a need code of 'child's disability'. Many other disabled children will come into the care system for other reasons. A looked after disabled child will not automatically be given a need code of 'child's disability' as there may be other categories of need which apply e.g. abuse or neglect or family dysfunction. Thus the official figures in England are an underestimation as they only show those looked after children for whom disability is the primary reason for intervention. Data on disabled children who use short break services are collected but not included in the looked after children figures in England.

In the continued absence of official statistics in England research provides some indicators of prevalence although few studies have focussed on the particular experiences of looked after disabled children, work has tended to study them as part of more general studies of the care system and thus are limited in detail. The largest study of the English care system (Sinclair et al. 2007) looked at movement and stability of children within the care system and identified disabled children as a distinct group. It is based on a large sample which is representative and covers all age groups and placement types. It found that groups of children differed in their chances of achieving a permanent placement and offers important insight into the experiences of disabled children in care. The study used three different definitions of disability: firstly, whether the child had a need code of disability $(3.5 \%$ of the sample); secondly, whether the local authority recorded information on child's disability on their IT recording system (7.7\%; local authority monitoring varied in how they defined disability) and finally, the social worker's opinion was sought via questionnaire as to whether in their opinion the child was disabled ( $17.7 \%$ of workers indicated the child was disabled) (Sinclair et al. 2007). The study clearly shows how different views of disability produce different prevalence rates.

One research study which had disabled children in care as its primary focus explored the permanence 
patterns of looked after disabled children (Baker, 2007). This study highlights the complexities involved in estimating the prevalence of looked after disabled children. The research examined the 'care careers' of a large sample $(n=596)$ of foster children over three years and looked at whether there were any particular difficulties in pursuing permanency for looked after disabled children. In order to identify the population of disabled children, the author had to first identify which of the foster children in the total sample were considered disabled. Using questionnaires, different respondents (e.g. social worker, foster carer or adopter depending on where the child was living) were asked if the child was considered disabled. In some cases all agreed the child either was (11\%) or was not (77\%) disabled. However in a number of cases people disagreed as to whether the child was disabled; a group the author called 'contested' (12\%). Analysis of possible reasons for this divergence of opinion showed that type of impairment was important; some respondents were waiting for a diagnosis before stating a child was disabled, for others it seemed that particular conditions led to dispute as to whether to classify as an impairment e.g. ADHD and attachment disorder. In other cases time was crucial; a child may have acquired a disability over the life course of the study due to an accident, late onset of conditions, changes in impact or advances in diagnosis. It was clear in the study that categorizing a child as disabled was not a neutral act. Whilst the study did not resolve the issue of how to estimate prevalence of looked after disabled children, it did offer transparency in how decisions were reached as to which children were counted as disabled.

In a review of the available evidence Baker (2007) estimated the prevalence of looked after disabled children to be between $10 \%$ and $25 \%$ based on research evidence available to date. Without national government statistics on looked after disabled children, we must continue to rely on a limited number of studies which do not cover this issue in sufficient depth and leads to an unclear picture of the numbers of looked after disabled children in England.

\section{Northern Ireland}


In Northern Ireland, the Department of Health, Social Services and Public Safety (DHSSPSNI) undertake annual surveys on children in care (OC2 survey) which provide information on disability. Each of the five Health and Social Care Trusts are asked to indicate how many children in care are disabled using the definition provided in the Disability Discrimination Act (1995) (see above). The latest survey that reported on prevalence of disability for children in care 2012/2013 (cared for continuously for 12 months or longer at 30 September 2013 ) found that $14 \%$ of looked after children and young people in Northern Ireland were disabled (DHSSPSNI 2014, p. 13), the same proportion as that for $2011 / 12$. This statistic compares with general population statistics show that approximately $6 \%$ of the population of children under 16 years in Northern Ireland are disabled (NISRA 2007, p. 16). The majority of disabled children in care had a learning disability (63\%) and a higher proportion of boys (17\%) than girls (12\%) were disabled. The survey also found that disabled children represented only $14 \%$ of all children in foster care (non-kinship or kinship); $26 \%$ of children in residential placements; and $18 \%$ in 'other' placements (DHSSPSNI, 2014: 13).

The Health and Social Care Board (HSCB) also produce six monthly statistical reports on Corporate Parenting Responsibilities and Delegated Statutory Functions based on data provided by the five Health and Social Care Trusts which provides information on looked after children. At 30th September 2013 , an estimated $12 \%$ of the looked after child population were reported to be disabled $(63 \%$ of these had a learning disability) (HSCB, 2013: 32). The Departmental statistics report on disabled children living in care for a continuous period of 12 months or more and the Board's statistics give a snapshot of the number of disabled children at a point in time (September or March of each year). However, both clearly indicate an over-representation of disabled children and young people in the care population.

In conclusion, the statistical data on looked after children in Northern Ireland consistently reports the over-representation of disabled children. However, as in other jurisdictions, ongoing challenges 
impact on the accuracy of the available statistics. Although the HSCB performs quality checks on the returns from each Trust, there are discrepancies in the numbers reported from each area (for example, low numbers of children with autism are reported in two Trust areas). In addition, the data Trusts provide are often based on records from their electronic social care database (soscare) which often only indicates whether or not a child is disabled on the basis of their access to disability services. Some disabled children living in care may not have access to specialist disability services and could, therefore, be under-reported. In addition, Trusts have differing organisational structures and processes with variances in the management of looked after disabled children's cases across Trusts. This may also lead to an inconsistent interpretation of disability across Trusts and challenges in aggregating data gathered using differing definitional parameters.

\section{Scotland}

The Scottish Government produce an annual Children Social Work Statistics report based on data extraction from all thirty-two local authority social work departments. For looked after children, data on the prevalence of disability are gathered at an individual child level and aggregated. As of July 2014, 15,580 children in Scotland were 'looked after' by local authorities (Scottish Government 2015). Local authorities recorded a 'primary additional support need' for 1,893 looked after children in Scotland (12\%); of these, 510 children are recorded as having 'multiple disabilities' (3.3\%), 274 children have a learning disability (with a further 46 having a specific learning disability), 146 children $(<1 \%)$ have an autistic spectrum disorder, 94 children have a physical or motor impairment and relatively small numbers have a visual or hearing impairment (48 and 12 respectively). The largest category includes 513 children recorded as having 'social, emotional and behavioural difficulties' (equates to $3.3 \%$ of the looked after child population). Furthermore, disability status is recorded as 'not known' or unrecorded for around $15 \%$ of all looked after children in Scotland (Scottish Government 2015). There are limited data on placement type and recorded disability. For example, although only a small minority of the total looked after child population, $94 \%$ of young people in secure care accommodation had at least 
one additional support need as of July 2014; a further analysis found $6 \%$ had specific learning difficulties, $16 \%$ had a visual impairment and $12 \%$ had a language and communication disorder (Scottish Government 2015).

There are limitations with the data available on looked after disabled children in Scotland. The reliability of individual child data gathered at a local level and then aggregated nationally is a concern; for example, there is variation in the interpretation of the different categories of disability across local authorities. It is worrying that for a significant number of looked after children (15\%) disability is not known or recorded. There has also been limited research in Scotland exploring the experiences of looked after disabled children and young people. There is some evidence that looked after disabled children are not receiving the same level of care planning as their non-disabled peers; for example, the Social Work Inspection Agency reported a disparity in the review of care plans of children looked after away from home: for non-disabled children, the rate was $92 \%$ compared to $71 \%$ of plans for disabled children (SWIA 2010). There is a need for national guidelines and practical support to ensure robust data is gathered, analysed and effectively utilised to plan and deliver services for looked after disabled children in Scotland.

\section{Wales}

There are limited data collection and research on looked after disabled children in Wales compared to the rest of the United Kingdom. To explore the prevalence of looked after disabled children in Wales, there are two main datasets. Firstly, 'Children in Need' (CIN) data are an annual return from all twenty-two local authorities based on individual records for children who have an open case with a local authority. Data are annually collected on $31^{\text {st }}$ March and only includes children who have had an open case for more than three months (1 January - 31 March). Local authorities record whether a child is looked after. The total number of children who were recorded as disabled and being looked after as of 31 March 2014 was 780 (Welsh Government 2015). Thus, 13.6\% of the total looked after 
child population ( $n=5755$ ) is recorded as disabled. Secondly, there is a national Children Looked After (CLA) database which pre-dates the CIN database. Similarly to the catergorisation of primary reasons in England, disability is one of the criteria for a child becoming looked after; as of $31^{\text {st }}$ March 2014, 25 children were looked after due to disability in Wales (Welsh Government 2014a).

There are serious limitations with the reliance on child datasets in Wales. The main Children in Need dataset is limited by the specific time frame of an open social work case file to include disabled children. This risks the likely exclusion of disabled children who do not have an open case file. As with Scotland, there is a reliance on local data entry systems that are subject to interpretation and human error. There will only be a small minority of children where disability is recorded as the primary reason for being looked after as similarly highlighted in the England. There are no known research studies on the prevalence of looked after disabled children in Wales to provide greater analysis and insight.

\section{Discussion}

The over-representation of disabled children in the looked after child population is reflected across UK jurisdictions and in the wider national and international research literature (Gordon et al. 2000; Sullivan \& Knutson 2000; Braddock et al. 2001; Read \& Harrison 2002; Trout et al. 2009; Stalker \& McArthur 2012; Lightfoot et al. 2011; Hillen 2012). However, despite consistent indications of overrepresentation in this population, there are acknowledged difficulties in accurately counting disabled children in the looked after child population. To explore this further, we now consider the definitional challenges and limitations in data reporting.

\section{Definitional Challenges}

The use of different legislative frameworks for defining looked after children and disability presents challenges for cross-comparisons. There is recognition of the different legal definitions for looked after 
children and data collection methods that must be addressed when comparing the four nations (Welsh Government 2014c). More specifically, the varying interpretations of disability present challenges in data synthesis as studies use differing points of departure. Gordon et al. (2000) highlight the variation in the reported number of looked after disabled children and suggest that this is due to uncertainty about definitions and measurements of disability. The authors state that this leads to a potential inflation of numbers as children with behavioural difficulties are at times included in the definition of disability. In Scotland, until 2012 the additional support needs category was presented as 'disability'. This was amended because the information collected does not meet the more limited definition of 'disability' in the Equality Act 2010. Definitions are susceptible to change over time and are interpreted within local policy contexts which add to the complexity of comparing data from the four nations.

There is variation of different categories of disability that are included in national reporting. Burns (2009) highlights the particular problems with definitions in that some studies include children and young people who solely have emotional and behavioural problems under the definition of disability and some include children with 'special educational needs' whilst others do not. For example, one category for disability in the Scottish dataset is 'social, emotional and behavioural problems' which accounts for the main disability for just over a quarter (27\%) of all looked after disabled children and young people. Similarly, mental health can be included or excluded from definitions of disability across jurisdictions. For example, this is evident in recent practice initiatives in Northern Ireland such as, reluctance to categorise children and young people as mentally ill due to the shift towards a recovery model of practice and a move away from clinical diagnosis of IQ or impairment toward an assessment of need to inform decisions about eligibility for access to services. The uncertainties about definition and measurement of 'disability' impede how we collect data which is essential for planning and delivering effective services for children and young people.

\section{Data Reporting Limitations}


All four nations rely on extrapolating data from multiple datasets to provide a snapshot of looked after disabled children. Across nations we have variation of between $3 \%$ and $14 \%$ of looked after children recorded as disabled in official statistics. Northern Ireland and Scotland provide the most comprehensive datasets for looked after children with annual returns including types of disability. In contrast, disability is only recorded in England for looked after children if this is the primary reason for state intervention. Therefore, some disabled children will be referred on primary grounds of abuse and neglect and will not be included in these annual returns. Similarly in Wales, disability must be a primary reason for referral to be recorded in the official statistics; therefore, only 25 children were looked after on the primary grounds of disability. As discussed, there are geographical variations in the quality of data-input with reliance on accurate up-to-date case records. As highlighted by Baker (2007), disability can be contested and a lack of agreement over diagnosis is likely to lead to reporting 'unknown' or 'unrecorded'. Particular problems reported by local authorities in recording numbers of looked after disabled children include the interface between definitions of disability and special educational needs; disagreements about levels of severity of certain impairments and the 'grey area' between disability and illness (Baker, 2007).

The official data available are in aggregate form and does not allow for any cross comparison of disabled and non-disabled looked after children. This severely restricts the level of information on disabled children that could be available based on the data collected and potentially affects the characteristics and outcomes reported for the looked after population as the impact of potentially different experiences for disabled children is not accounted for when the population is treated as a homogenous group. This is of particular concern as the limited studies which have explored looked after disabled children's experiences have shown some evidence of different placement patterns; disabled children may stay in care for longer, may be more likely to be inappropriately placed, they may be more likely to live in residential care, have fewer adoption opportunities and struggle at 
transition from care. Such critical policy and practice areas could be examined if the national looked after datasets recorded child's disability and cross referenced this with other information collected.

Ways forward: Recommendations and Implications

This paper highlights the difficulties in establishing accurate prevalence figures for disabled children who are also looked after across the United Kingdom. The general lack of scrutiny of how many looked after children are disabled strongly indicates a continued oversight of this distinct group of children in the looked after child population. This is particularly striking by the absence of recording in England whether or not a looked after child is disabled compared to recording in Scotland, Northern Ireland and Wales indicating broadly similar rates of between $12 \%$ and $14 \%$. In England the sole reliance of recording a child's disability where this is the primary reason for the child becoming looked after ( $3 \%$ of looked after children) overlooks a significant group of children who are referred due to abuse and neglect, and also have a disability. Despite concerns that appropriate long term care planning for disabled children has been limited, we remain severely limited by the available data to compare outcomes for disabled children to non-disabled children in care (Baker 2011; Cousins 2006; Grant \& Thomas 2013; Morris 1995).

The absence of accurate information impacts on the development of services to effectively meet the needs of this group. This is part of a wider challenge on the lack of accurate data on disability; as Gordon (2000, p. 269) argues:

We lack basic demographic information on disability in childhood. We have less statistical information about them than any other group. This scandalous lack of basic information will have to be made good. Unless it is, an informed well-planned and vigorous improvement in policy and practice is unlikely to be feasible.

An English study exploring prevalence, characteristics and service provision for disabled children found due to the varying sources of data available to local authorities, the lack of a consistent definition of disability, and the different categorisations and interpretations of service provision, it is not possible 
to assess accurately the level of health and social care services provided for disabled children and their families (Mooney 2008, p. 78-79). Several authors have called for an improvement in available statistics on the population of looked after disabled children to enable more effective service planning (Baker 2011; Burns 2009; Grant \& Thomas 2013; Mooney et al. 2008; Read et al. 2009; Stuart \& Baines 2004). For example, the lack of statistical data hinders permanence planning for disabled children and comparisons with non-disabled peers in care (Grant \& Thomas 2013). Therefore, there is a very limited ability to map current service provision for looked after disabled children and identify any gaps to develop future services for this cohort of children.

There are several recommendations to strengthen the robustness and comparability of data collected on looked after disabled children across the United Kingdom. Firstly, definitional clarity and consistent terminology using the UNCRPD (2007) or equality legislation would be useful to facilitate cross comparison. Developing definitional clarity that considers the views of disabled children and young people themselves with a focus on their perception of need would be highly valued. As discussed in Northern Ireland and Scotland, there is particular variance in the inclusion of social, emotional and behavioural difficulties and mental health issues. Secondly, providing guidance for data inputting to ensure disability is appropriately recorded and ensuring adequate resources would improve the annual returns from each jurisdiction. In Northern Ireland, a child had to be accessing a disability service for their disability to be recorded in the annual returns which is likely to underestimate the population. Such developments could incorporate mechanisms for disaggregating data for disabled and non-disabled looked after children; and for the collection of further information on discrete subpopulations. For example, Scotland provides a breakdown of additional support needs of the relatively small number of young people in secure care settings. It would be helpful to have further analysis of looked after disabled children by placement type, number of placements and final destinations of children. Greater identification of disability by placement type could potentially assist in targeting appropriate support to children, carers and birth families (as appropriate). Thirdly, in England and 
Wales it would be helpful for the multiple reasons for social care involvement to be recorded rather than only one primary reason. As discussed, this categorisation is highly likely to underestimate the numbers of looked after disabled children as their entry into care is recorded under a different primary reason (for example, abuse and neglect). As research has indicated the higher prevalence of abuse of disabled children compared to non-disabled children (Jones et al. 2012; Stalker \& McArthur 2012; Sullivan \& Knutson 2000), this oversight of dual recording is particularly concerning. Finally, investment and commitment to data collection for disabled children more widely would provide a greater set of comparative data (Mooney et al. 2008). This would allow for data linkages to other sources of information on disabled children within and across jurisdictions. In addition, there should be opportunities for statisticians in the different jurisdictions to engage in dialogue about data collection and data analysis in respect to looked after disabled children to improve cross-comparative opportunities.

To conclude, without robust data we cannot compare the progress and areas of improvement we need to aspire to for our looked after disabled children in all aspects of their lives. Until this happens, the presence of disabled children in the looked after system will continue to be overlooked, disabled looked after children's views, wishes and experiences will continue to be obscured and those with responsibilities for parenting these children will continue to lack the basic data on which they need to ensure their needs are met and rights are upheld.

\section{References}

Argent, H (1996) The Placement of Children with Disabilities - Practice Note 34. BAAF, London. 
Argent, H (1998) Whatever Happened to Adam? Stories of Disabled People who were Adopted or Fostered. BAAF, London.

Baker, C (2011) Permanence and stability for disabled looked after children. IRISS, Glasgow.

Baker, C. (2007) Disabled children's experience of permanency in the looked after system. British Journal of Social Work, 37, 1173-1188.

Braddock, D., Emerson, E., Felce, D. \& Stancliffe, R. J. (2001) Living circumstances of children and adults with mental retardation or developmental disabilities in the United States, Canada, England and Wales, and Australia. Mental Retardation and Developmental Disabilities Research Reviews, 7, 115121.

Burns, C. (2009) Disabled Children Living Away From Home: In Foster Care and Residential Setting. MacKeith Press, London.

Cousins, J (2006) Every Child is Special: Placing Disabled Children for Permanence. BAAF, London.

Department of Education Northern Ireland (2013) Special Education Needs (SEN) pupils by ELB 2013/14. Department of Education Northern Ireland, Belfast.

Department for Education (2014) Children Looked After in England (including adoption and care leavers) - year ending 31 March 2014. Department for Education (DfE), London.

Department for Education (2014) Children Looked after by Local Authorities in England: Guide to the SSDA903 collection 1 April 2014 to 31 March 2015. Department for Education (DfE), London.

Department for Work and Pensions (2013) Family Resources Survey: United Kingdom 2011/12. Department for Work and Pensions (DWP), London.

Department of Health, Social Services and Public Safety Northern Ireland (2014) Children's Social Care in Northern Ireland 2012-13: Statistical Bulletin. DHSSPSNI, Belfast.

Dowling, S., Kelly, B. \& Winter, K. (2013) Disabled Children and Young People who are Looked After: A Literature Review. Office of the First Minister and Deputy First Minister (OFMDFM) and Queen's University, Belfast.

Gordon, D., Parker, R. \& Loughrin, F. (2000) Disabled Children in Britain: A Re-analysis of the OPCS Disability Survey. Stationery Office, London.

Grant, M \& Thomas, C (2013) Adoption of Disabled Children. BAAF, London.

Health and Social Care Board (2013) Corporate Parenting Statistical Report: 30th September 2013. HSCB, Belfast.

Hershkowitz, I., Lamb, M.E. \& Horowitz, D. (2007) Victimization of children with disabilities. American Journal of Orthopsychiatry 77(4), 629-635.

Hillen, T. (2012) Assessing the prevalence of mental health disorders and mental health needs among preschool children in care in England. Infant Mental Health Journal, 33(4), 411-420. 
Jones, L., Bellis, MA., Wood, S., Hughes, K., McCoy, E., Eckley, L., Bates, G., Mikton, C., Shakespeare, T. \& Officer, A. (2012) Prevalence and risk of violence against children with disabilities: a systematic review and meta-analysis of observational studies. The Lancet, 380, 899-907.

Kelly, B., Dowling, S. and Winter, K. (2014) A Review of the Legislative and Policy Context in relation to Looked After Disabled Children and Young People in Northern Ireland. OFMDFM and Queen's University Belfast.

Lightfoot, E. Hill, K. \& LaLiberte, T. (2011) Prevalence of children with disabilities in the child welfare system and out of home placement: an examination of administrative records. Children and Youth Services Review, 33, 2069-2075.

McGill, P., Tennyson, A \& Cooper, V (2006) Parents whose children with learning disabilities and challenging behaviour attend 52-week a year residential schools: their perceptions of services received and expectations for the future. British Journal of Social Work 36, 597-616.

Milligan, I. \& Stevens, I. (2006) Residential Child Care: Collaborative Practice. Sage, London.

Mooney, A., Owen, C. \& Statham, J (2008) Disabled Children: Numbers, Characteristics and Local Service Provision. Department for Children, Schools and Families, London.

Morris, J (1995) Gone Missing?: A Research and Policy Review of Disabled Children Living Away from their Families. Who Cares? Trust, London.

Northern Ireland Statistics and Research Agency (2007) The Prevalence of Disability and Activity Limitations amongst Adults and Children Living in Private Households in Northern Ireland. First Report from the Northern Ireland Survey of People with Activity Limitations and Disabilities. NISRA, Belfast.

Read, J. \& Harrison, C. (2002) Disabled children living away from home in the UK: recognising hazards and promoting good practice. Journal of Social Work, 2(2), 211-231.

Read, J., Blackburn, C. \& Spencer, N. (2009) Disabled children in the UK: a quality assessment of quantitative data sources. Child: Care, Health and Development 36 (1), 130-141

Scottish Government (2014) Children's Social Work Statistics 2012-2013 and Additional Tables. Scottish Government, Edinburgh.

Scottish Government (2015) Children's Social Work Statistics 2013-2014 and Additional Tables. Scottish Government, Edinburgh.

Sinclair, I, Baker, C, Lee, J and Gibbs, I (2007) The Pursuit of Permanence: A Study of the English Care System. Jessica Kingsley, London.

Smith, M. (2009) Rethinking Residential Child Care: Positive Perspectives. Policy Press, Bristol.

Social Work Inspection Agency (2010) Improving Social Work in Scotland: A report on SWIA's report inspection programme 2005-2009. SWIA, Edinburgh.

Spencer, N., Devereux, E., Wallace, A., Sundrum, R., Shenoy, M., Bacchus, C. \& Logan, S. (2005) Disabling conditions and registration for children abuse and neglect: a population study. Pediatrics, 116 (3), 609-613. 
Stalker, K. \& McArthur, K. (2012) Child abuse, child protection and disabled children: a review of recent research. Child Abuse Review, 21, 24-40.

Stuart, M \& Baines, C (2004) Progress on Safeguards for Children Living Away from Home A Review of Actions Since the People Like Us Report. Joseph Rowntree Foundation, York.

Sullivan, P. M. \& Knutson, J. (2000) The association between child maltreatment and disabilities in a hospital-based epidemiological study. Child Abuse \& Neglect, 22, 271-288.

Trout, A. L., Casey, K., Chmelka, M.B., DeSalvo, C., Reid, R. \& Epstein, M.H. (2009) Overlooked: children with disabilities in residential care. Child Welfare League of America, 88(2), 111- 136.

Welsh Government (2014a) Children Looked After by 31 March 2014 by Local Authority, Gender and Age. Knowledge and Analytical Services, StatsWales, Cardiff.

Welsh Government (2014b) Respite Care for Looked After Children, by Placement, year ending 31 March and Respite Care for Looked After Children by Local Authority and Need of Care. Knowledge and Analytical Services, StatsWales, Cardiff.

Welsh Government (2014c) A review of the comparability of statistics of children looked after by local authorities in the different countries of the United Kingdom. Knowledge and Analytical Services, StatsWales, Cardiff.

Welsh Government (2015) Children in Need Census (CARE0103: Children in Need at 31 March by Looked After Status, Category of Need and Disability, Including Unborn Children). Knowledge and Analytical Services, StatsWales, Cardiff. 